生物教研室引进细胞株生产 的 OKT11 样 单克隆抗体能沉淀人外周血淋巴细胞表面 50000 的抗原, 与标准 CD2 系列抗体沉腚 的抗原相同。

2. 用此 $O K T 111, G$ 制备免疫吸附柱所 提取的人 $C D 2$ 抗原并非单一组分. 用 $S D S-$ $P A G E(+2 M E)$ 法证明,除 50000 成分外, 还有 66000 及小于 40000 的组分.

3. 所提 $C D 2$ 抗原能完全或部分恢复经 $45^{\circ} \mathrm{C}$ 处理的扁桃体细胞的 $E$ 玫瑰花形成率; 当它与 $S R B C$ 孵育后, 对人淋巴细胞 $E$ 玫 瑰花形成抑制率达 $43.4 \%$ 。
4. 经放射免疫法和 ELISA 法证明, 所 提 $C D 2$ 抗原与 $O K T 11$ 抗体之间存在特异 性反应。

5. 建立了测定 $E^{+}$淋巴细胞表面 $C D 2$ 抗原数量的竞争性 ELISA 法, 并测出每个 人扁桃体 $E^{+}$淋巴细胞表面 $C D 2$ 抗原分子 数为 $11.7 \times 10^{4} \pm 6.4 \times 10^{4}$.

对 $C D 2$ 抗原的研究不仅有助于阐明 $T$ 细胞活性调节的基础理论问题，而且有一定 临床应用价值, 因此引起人们广泛注意。

刘亚霞 沈倍奋 吴 蔚

（军束医学科学院基础医学研究所, 北京)

\title{
用微机对果树合理密植优化模拟设计
}

果树合理密植应根据树体特性、自然环 境和栽培技术，既节约用地，又合理利用空间 和光能, 充分发挥整个叶幕的光合生产能力, 达到丰产、稳产、优质、低耗费之最终目的. 果树之间的遮光主要决定于树体大小、栽植 密度、坡度 $\alpha$ 、坡向 $\beta$ 、纬度 $\varphi$ 、太阳视赤纬 8 及时角 $\omega$ 等因素. 各种果树必须的受光条件 可依据其光合作用的需光情况来确定. 在传 统的果树栽培中，仅凭经验决定果树栽植密 度, 存在着很大的主观盲目性, 但至今未有新 的突破。

本研究把果树叶幕看成一个需光系统, 根据上述影响果树间遮光的因素, 推导出果 树叶幕对行间和株间遮光系数的计算公式分 别为:

$$
\begin{aligned}
& C_{\mathrm{x}, \alpha, \beta}=\sin (A-\beta) /(\sin \alpha+\cos \alpha \cdot \operatorname{tg} h) \text {, } \\
& C_{y, \alpha, \beta}=\cos (A-\beta) /(\sin \alpha+\cos \alpha \cdot \operatorname{tg} h) \text {. } \\
& A=\arcsin (\cos \delta \cdot \sin \omega / \cos h) \text {, } \\
& h=\arcsin (\sin \varphi \cdot \sin \delta \\
& +\cos \varphi \cdot \cos \delta \cdot \cos \omega) \text {. }
\end{aligned}
$$

从而建立起果树合理密植的优化数 学模 型, 行距 $(\mathrm{m})$ :

$$
X_{\text {opt. }}=C_{\mathrm{x}, \alpha, \beta} \cdot H_{\mathrm{opt}}+D_{\mathrm{opt}} / 2,
$$

株距 (m):

$$
Y_{\text {opt. }}=C_{Y, a, \beta} \cdot H_{\text {opt }}+D_{\text {opt }} / 2,
$$

密度(株/ha):

$$
Z_{\text {opt. }}=10,000 / X_{\text {opt. }} \cdot Y_{\text {opt. }},
$$

其中 $H_{\text {opt. }}$ 和 $D_{\text {opt. }}$ 为果树叶幕高度和直径. 经 Z-80C 型微机系统用 BASIC 程序对上 述模型计算的数据，与用 $D_{\mathrm{j} 6-1}$ 型经纬仪对 标杆日影的实测结果无显著差异. 用实地调 查资料算出 $31^{\circ} \mathrm{N}$ 平地上栽植果梅树 (Prunus mume Sieb. et Zucc.) 的合理密度是 $450-720$ 株/ ha, 其行、株距之比约 2:1. 这 与当前提倡的果树篦壁形密植要求相符.

本研究方法简便易行; 计算快速、精确、 客观,有充分的科学依据;所建立的数学模型 不仅能用于确定不同果树在各地栽培的合理 密度,而且还能指导其它高杆作物合理密植， 及设计行道遮光树木和温室等需光建筑时 参考。

\section{陈 凯}

（江苏省植物研究所，南宗）

胡国谦江广恒

（南京农业大学）

周武忠

（江苏农学院,扬州） 